\title{
Evaluation of the effects of Bambusa tulda on osteogenic differentiation and mineralization of human stem cells.
}

\author{
Hyunjin Lee ${ }^{1}$, Md. Salah Uddin², Sang Woo Lee ${ }^{3}$, Sangho Choi ${ }^{3}$, Jun-Beom Park ${ }^{*}$ \\ ${ }^{1}$ Department of Periodontics, College of Medicine, Catholic University of Korea, Seoul, Republic of Korea \\ ${ }^{2}$ Ethnobotanical Database of Bangladesh, People's Republic of Bangladesh \\ ${ }^{3}$ International Biological Material Research Center, Korea Research Institute of Bioscience and Biotechnology, \\ Daejeon, Republic of Korea
}

\begin{abstract}
Bambusa tulda has been used for various Purpose and is considerd as one of the most useful bamboo species. This study aimed to evaluate the effects of Bambusa tulda extract (BBT) on the osteogenic differentiation and mineralization of human mesenchymal stem cells. Stem cells obtained from gingivae were cultured in an osteogenic medium in the presence of BBT at concentrations ranging from $0.001 \%$ to $1 \%$. Evaluations of cell morphology and cellular viability were done at days $1,3,5$ and 7 . Alkaline phosphatase activity assays and Alizarin red $S$ staining were performed to evaluate the osteogenic differentiation of stem cells. The morphology of stem cells in the presence of BBT at final concentrations of $0 \%, 0.001 \%, 0.01 \%, 0.1 \%$, and $1 \%$ did not show any noticeable changes when compared with the untreated control group. The treatment of BBT (from $0.001 \%$ to $1 \%$ groups) showed decrease in alkaline phosphatase activity. The results of the Alizarin Red S staining showed a significant decrease with application of BBT. Conclusively, Bambusa tulda had influenced the osteogenic differentiation of the stem cells derived from the gingiva. Thus, the use of Bambusa tulda may produce adverse effects onto oral tissues. The concentration and application time of Bambusa tulda should be meticulously controlled to minimize the adverse effects.
\end{abstract}

Keywords: Bambusa, Cell differentiation, Cell survival, Herbal medicine, Medical plants, Stem cells.

Accepted on June 092017

\section{Introduction}

Herbal medicines are widely used for treating the various kinds of diseases and generally regarded as safe due to their extensive use in Traditional Medicine practice for thousands of years [1-3]. Many plants are shown to possess antimicrobiological and anti-inflammatory functions and they have been applied for the the treatment of flatulence, jaundice, menstrual difficulties, hematuria, hemorrhage, and colic [4]. More recently, potential role of herbal medicine on stem cell have been tested in vitro and in vivo experiments [5]. One of the traditional Chinese herbal medicine, Sarcandra glabra is reported to protect mesenchymal stem cells from oxidative stress [6]. Icariin, derived from Epimedium is shown to effectively alleviate nephrectomy induced chronic renal failure through increasing renal stem cells [7]. However, the traditional Chinese medicine formula, Pien Tze Huang inhibited the proliferation, and induced the apoptosis and differentiation of cancer stem cells via suppression of the Notch1 pathway [8].

Bambusa tulda Roxburgh has been widely used and it is considered one of the most useful bamboo species [9]. It is native to Indian subcontinent, Indochina, Tibet, and Yunnan [10]. Bambusa tulda has nutritive shoots and it is widely consumed as edible bamboos in Asia [11]. However, within the authors' knowledge, the effects of extracts of Bambusa tulda on differentiation of stem cells have not been revealed yet. This study aimed to evaluate the effects of Bambusa tulda extract (BBT) on the osteogenic differentiation and mineralization of human mesenchymal stem cells.

\section{Material and Methods}

\section{Preparation of plant materials}

Bambusa tulda Roxburgh was collected by Vashkar Chowdhury from Amki village, Sonaimuri Upazilla, Noakhali District, Bangladesh. A voucher specimen recoded as PB022073 was deposited in the herbarium of the Korea Research Institute of Bioscience and Biotechnology. After drying and grinding leaves of Bambusa tulda, the powder (63 g) was added to $500 \mathrm{~mL}$ of methanol. The method of repercolation at room temperature was used for the extraction method. The extract was filtered and concentrated by rotavapor 
under reduced pressure, thereby obtaining $2.75 \mathrm{~g}$ of Bambusa tulda methanolic extract (BBT).

\section{Stem cells isolated from human gingiva}

The gingivae were obtained from healthy patients visiting the Department of Periodontics, Seoul St. Mary's Hospital, College of Medicine, the Catholic University of Korea. The approval number of the Institutional Review Board is KC11SISI0348 and informed consents were obtained from the participants. This study was performed in accordance with the relevant guidelines and regulations. De-epithelialization of the gingivae was done and fragmentation of the tissue was done into 1-2 mm fragments. Dispase (1 mg/ml; Sigma-Aldrich Co., St. Louis, MO, USA) and collagenase IV (2 mg/mL; SigmaAldrich Co.) were used for the digestion of fragmented gingivae [10]. Unattached cells were removed from the plates. The media was changed every 2 to 3 days and cells were incubated with $5 \% \mathrm{CO}_{2}$ and $95 \% \mathrm{O}_{2}$ in $37^{\circ} \mathrm{C}$ incubator.

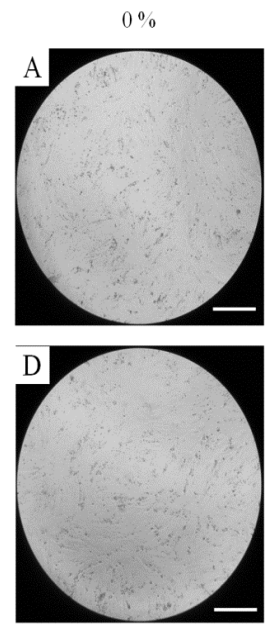

$0.1 \%$
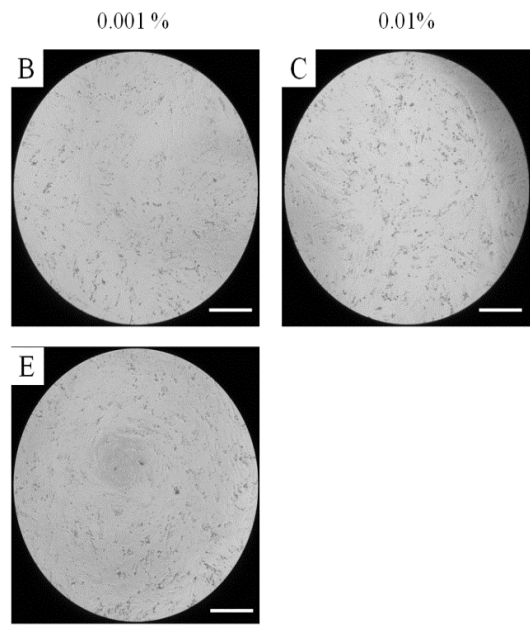

$1 \%$
Figure 1. Evaluation of cell morphology on day 1 using inverted microscopy following treatment with different concentrations of BBT in osteogenic media. A) Control group (original magnification 200X); B) $0.001 \%$ group (original magnification $200 X$ ); C) $0.01 \%$ group (original magnification 200X); D) $0.1 \%$ group (original magnification 200X); E) $1 \%$ group (original magnification 200X). The bar indicates $200 \mu \mathrm{m}$.

\section{Evaluation of cellular morphology}

Stem cells were plated at a density of $2.0 \times 10^{3}$ cells/well and cultured in an osteogenic medium (alpha-minimal essential medium ( $\alpha$-MEM, Gibco, Grand Island, NY, USA) supplemented with 15\% fetal bovine serum (FBS, Gibco), 200 mM L-glutamine (Sigma-Aldrich Co.), $10 \mathrm{mM}$ of ascorbic acid 2-phosphate (Sigma-Aldrich Co.), $38 \mu \mathrm{g} / \mathrm{ml}$ of dexamethasone, $2 \mathrm{mg} / \mathrm{ml}$ of glycerophosphate disodium salt hydrate, and 100 $\mathrm{U} / \mathrm{mL}$ penicillin, and $100 \mu \mathrm{g} / \mathrm{mL}$ streptomycin (Sigma-Aldrich Co.)). The final concentrations of BBT were $0 \%, 0.001 \%$, $0.01 \%, 0.1 \%$, and $1 \%$, respectively. On days $1,3,5$ and 7 , the morphological evaluation was performed using inverted microscopy (CKX41SF, Olympus Corporation, Tokyo, Japan).

\section{Evaluation of cellular viability}

On days $1,3,5$, and 7 , the evaluation of cellular viability was performed according to the previous report using the Counting Kit-8 (CCK-8, Dojindo, Tokyo, Japan) assay [11]. In short, cells were incubated with tetrazolium monosodium salt for $2 \mathrm{~h}$ at $37^{\circ} \mathrm{C}$. Spectrophotometric absorbance at $450 \mathrm{~nm}$ was done using a microplate reader (BioTek Instruments Inc., Winooski, VT, USA).

\section{Alkaline phosphatase activity assays}

On days 3 and 7, alkaline phosphatase activity assays were done using a commercially available kit (K412-500, BioVision, Inc., Milpitas, CA, USA). A microplate reader (BioTek Instruments Inc.) was used to measure the spectrophotometric absorbance of the samples.

\section{Evaluation of Alizarin Red S staining}

On days 3, 7, and 14, Alizarin Red S staining was performed. The cells were washed, fixed, and stained with 2\% Alizarin Red S Solution (ScienCell Research Laboratories, Inc., Carlsbad, CA, USA) and evaluated with a microscope (CKX41SF, Olympus Corporation). Ten percent cetylpyridinium chloride (Sigma-Aldrich Co.) was used to solubilize the bound dye, and spectrophotometric quantification was performed at $560 \mathrm{~nm}$ (BioTek Instruments Inc.).

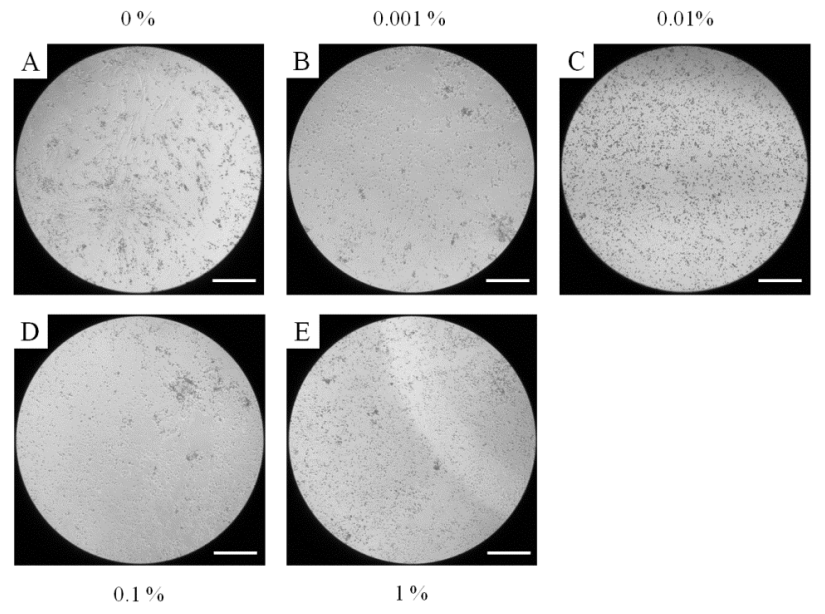

Figure 2. Evaluation of cell morphology on day 3 using inverted microscopy following treatment with different concentrations of BBT in osteogenic media. A) Control group (original magnification 200X); B) $0.001 \%$ group (original magnification 200X); C) $0.01 \%$ group (original magnification 200X); D) $0.1 \%$ group (original magnification 200X); E) 1\% group (original magnification 200X). The bar indicates $200 \mu \mathrm{m}$.

\section{Statistical analysis}

The data were shown as mean \pm standard deviation of the experiments. A test of normality was performed, and a oneway analysis of variance with post hoc Tukey's test was performed to determine the differences between the groups using a commercially available program (SPSS 12 for 
Windows, SPSS Inc., Chicago, IL, USA). The level of significance was considered 0.05 .

\section{Results}

\section{Evaluation of cell morphology}

The morphology of stem cells treated with BBT at final concentrations of $0 \%, 0.001 \%, 0.01 \%, 0.1 \%$, and $1 \%$ on day 1 is shown in Figure 1. Stem cells in the control group showed fibroblast-like morphology on day 1 (Figure 1). The morphology of stem cells in the presence of BBT at final concentrations of $0 \%, 0.001 \%, 0.01 \%, 0.1 \%$, and $1 \%$ did show noticeable changes when compared with the untreated control group (Figures 2-4).

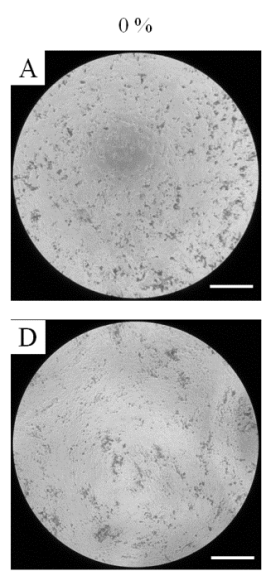

$0.1 \%$
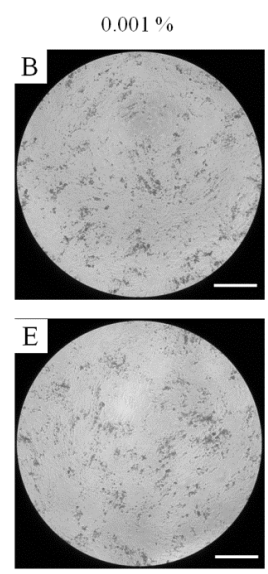

$1 \%$

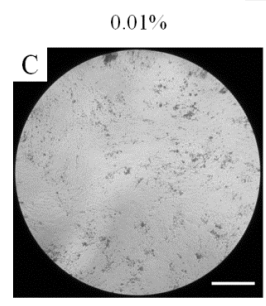

Figure 3. Evaluation of cell morphology on day 5 using inverted microscopy following treatment with different concentrations of BBT in osteogenic media. A) Control group (original magnification 200X); B) $0.001 \%$ group (original magnification 200X); C) $0.01 \%$ group (original magnification 200X); D) $0.1 \%$ group (original magnification 200X); E) 1\% group (original magnification 200X); The bar indicates $200 \mu \mathrm{m}$.

\section{Cellular viability}

Results from the CCK8 assay revealed cellular viability on days 1, 3, 5 and 7 which are shown in Figure 5. The relative values of CCK-8 on day 1 for $0.001 \%, 0.01 \%, 0.1 \%$ and $1 \%$ are $72.2 \% \pm 8.2 \%, 81.5 \% \pm 7.4 \%, 79.2 \% \pm 1.2 \%, 74.1 \% \pm$ $6.2 \%$, and $68.5 \% \pm 8.7 \%$, respectively, when the control $(0 \%)$ group on day 1 is considered $100 \%(100.0 \% \pm 5.7 \%)(\mathrm{P}<0.05)$ (Figure 5A). The relative values of CCK- 8 on day 3 for $0.001 \%, 0.01 \%, 0.1 \%$ and $1 \%$ are $81.2 \% \pm 7.1 \%, 65.2 \% \pm$ $9.5 \%, 77.6 \% \pm 4.5 \%, 71.0 \% \pm 4.1 \%$, and $90.6 \% \pm 35.3 \%$, respectively, whereas the control $(0 \%)$ group on day 3 is considered 100\% $(100.0 \% \pm 1.7 \%)(\mathrm{P}<0.05)$ (Figure $5 \mathrm{~B})$. The relative values of CCK- 8 on day 5 for $0.001 \%, 0.01 \%, 0.1 \%$ and $1 \%$ are $91.4 \% \pm 1.9 \%, 97.7 \% \pm 5.7 \%, 92.5 \% \pm 0.1 \%$, $92.5 \% \pm 0.7 \%$, and $94.5 \% \pm 1.1 \%$, respectively, whereas the control $(0 \%)$ group on day 5 is considered $100 \%(100.0 \% \pm$ $3.9 \%$ ) (Figure $5 \mathrm{C}$ ). The relative values of CCK-8 on day 5 for $0.001 \%, 0.01 \%, 0.1 \%$ and $1 \%$ are $47.9 \% \pm 0.5 \%, 44.5 \% \pm$ $0.7 \%, 45.9 \% \pm 0.2 \%, 42.1 \% \pm 0.7 \%$, and $42.8 \% \pm 0.2 \%$, respectively, whereas the control $(0 \%)$ group at day 7 is considered 100\% $(100.0 \% \pm 1.5 \%)(\mathrm{P}<0.05)$ (Figure 5D).
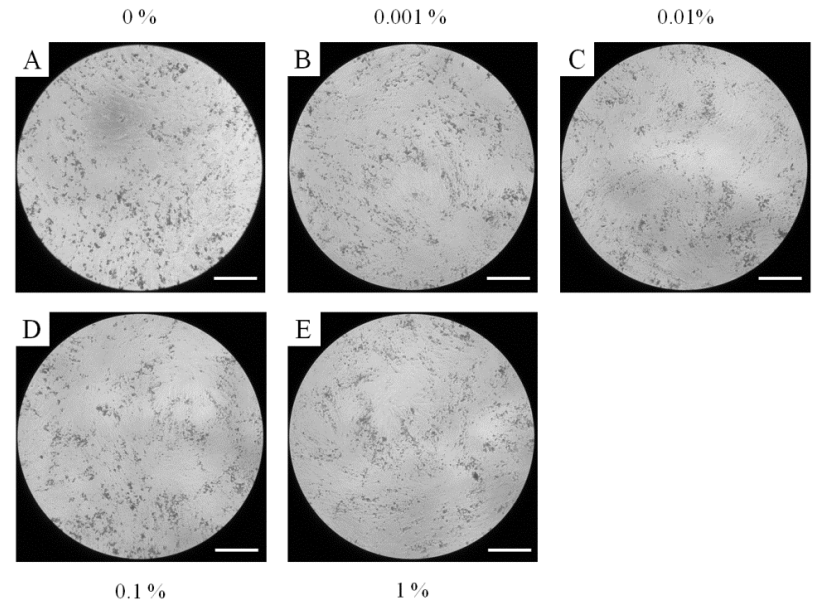

Figure 4. Evaluation of cell morphology on day 7 using inverted microscopy following treatment with different concentrations of BBT in osteogenic media. A) Control group (original magnification 200X); B) $0.001 \%$ group (original magnification 200X); C) $0.01 \%$ group (original magnification 200X); D) $0.1 \%$ group (original magnification 200X); E) 1\% group (original magnification 200X). The bar indicates $200 \mu \mathrm{m}$.

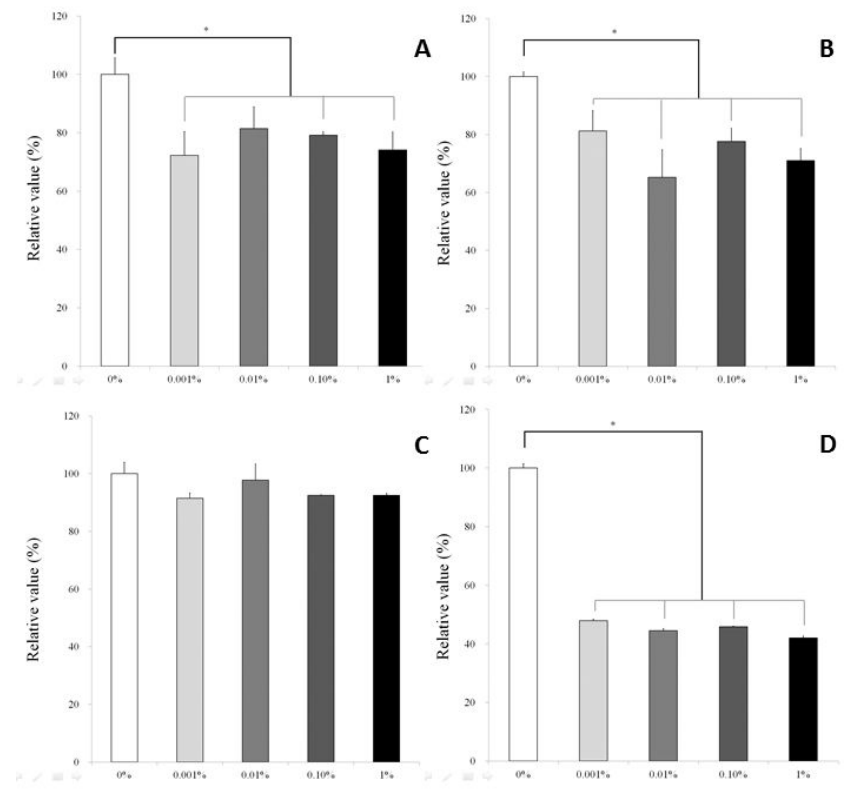

Figure 5. The CCK-8 assay results cultured with osteogenic media. A) Day 1; B) Day 3; C) Day 5; D) Day 7.

\section{Alkaline phosphatase activity assays}

The alkaline phosphatase activity treated with BBT at days 3 and 7 is shown in Figure 6 . The absorbance values of cells on day 3 cultured with $0 \%, 0.001 \%, 0.01 \%, 0.1 \%$, and $1 \%$ BBT were $0.083 \pm 0.001,0.089 \pm 0.006,0.076 \pm 0.000,0.085 \pm$ $0.001,0.091 \pm 0.001$, and $0.076 \pm 0.001$, respectively. The absorbance values of cells on day 7 cultured with $0 \%, 0.001 \%$, $0.01 \%, 0.1 \%$, and $1 \%$ BBT were $0.102 \pm 0.001,0.095 \pm 0.000$, $0.096 \pm 0.001,0.098 \pm 0.001,0.089 \pm 0.003$, and $0.087 \pm$ 
0.001 , respectively. The treatment of BBT (from $0.001 \%$ to $1 \%$ groups) showed decrease in alkaline phosphatase activity but this did not reach statistical significance at day 7 .

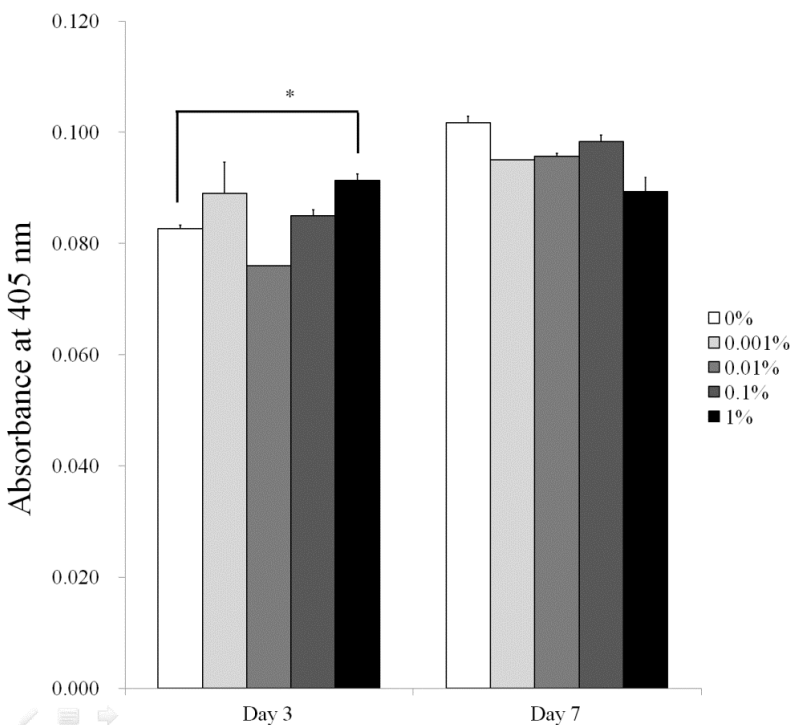

Figure 6. Alkaline phosphatase activity on days 3 and 7.

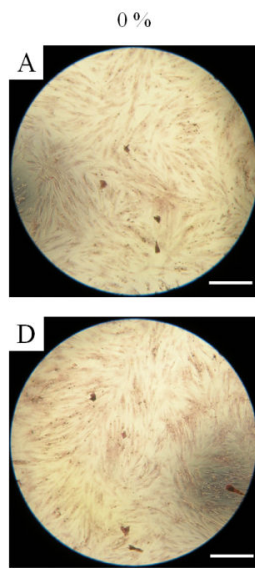

$0.1 \%$
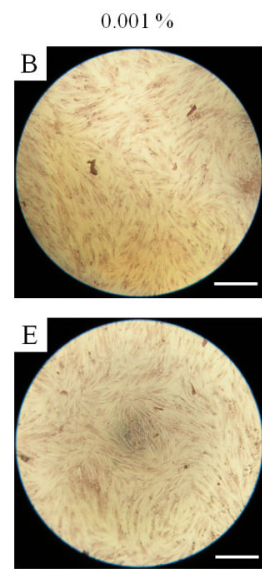

$1 \%$

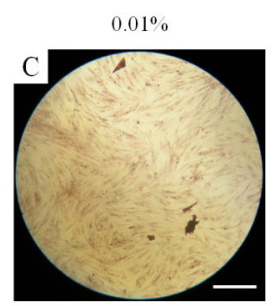

Figure 7. Results of Alizarin Red S staining on day 3 following treatment with different concentrations of BBT on osteogenic supplement. A) Control group (original magnification 100X); B) $0.001 \%$ group (original magnification $100 \mathrm{X}$ ); C) $0.01 \%$ group (original magnification $100 X$ ); D) $0.1 \%$ group (original magnification 100X); E) $1 \%$ group (original magnification 100X). The bar indicates $400 \mu \mathrm{m}$.

\section{Mineralization assay}

The results of the Alizarin Red S staining on days 3, 7 and 14 following treatment with different concentrations of BBT in an osteogenic supplement are shown in Figures 7-9. The absorbance of cells on day 3 cultured with $0 \%, 0.001 \%, 0.01 \%$, $0.1 \%$, and $1 \%$ BBT was $0.053 \pm 0.002,0.064 \pm 0.009,0.060 \pm$ $0.005,0.074 \pm 0.017$, and $0.051 \pm 0.003$, respectively (Figure 10). The absorbance of cells on day 7 cultured with $0 \%, 0 \%$, $0.001 \%, 0.01 \%, 0.1 \%$, and $1 \%$ BBT was $0.107 \pm 0.001,0.102$ $\pm 0.004,0.096 \pm 0.005,0.094 \pm 0.013$, and $0.102 \pm 0.001$, respectively (Figure 10). The absorbance of cells on day 14 cultured with $0 \%, 0.01 \%, 0.1 \%$, and $1 \%$ BBT was $0.250 \pm$ $0.004,0.098 \pm 0.003,0.085 \pm 0.001,0.096 \pm 0.003$, and 0.100 \pm 0.011 , respectively. A statistically significant decrease of absorbance was noted with application of BBT on day 14 $(\mathrm{P}<0.05)$ (Figure 10).
$0 \%$
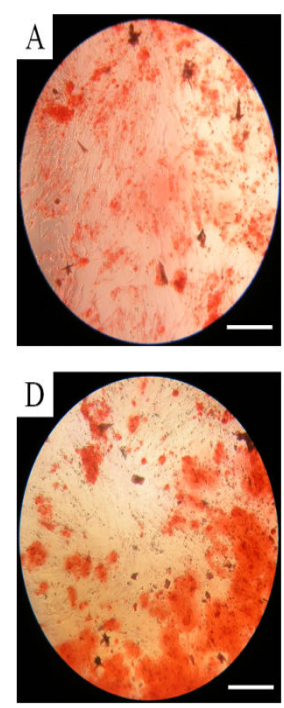

$0.1 \%$
$0.001 \%$
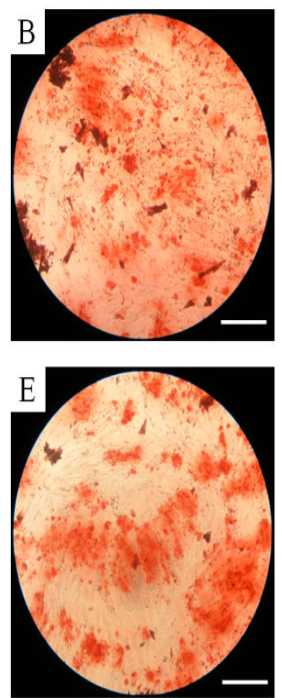

$1 \%$
Figure 8. Results of Alizarin Red S staining on day 7 following treatment with different concentrations of $B B T$ on osteogenic supplement. A) Control group (original magnification 100X); B) $0.001 \%$ group (original magnification $100 \mathrm{X}$ ); C) $0.01 \%$ group (original magnification 100X); D) $0.1 \%$ group (original magnification 100X); E) $1 \%$ group (original magnification 100X). The bar indicates $400 \mu \mathrm{m}$.

\section{Discussion}

This report discusses the effects of different concentrations of BBT on the osteogenic differentiation of stem cells derived from human gingival tissues. This study clearly showed that the application of Bambusa tulda decreased mesenchymal stem cells. In previous reports, mesenchyamal stromal cells are treated with individual and mixtures of crude herbal extracts, as well as with purified compounds from herbal extracts, to investigate the mechanisms and effects of differentiation of stem cells [5,12-15]. Er-Xian Decoction, a traditional Chinese herbal formula widely used for postmenopausal osteoporosis treatment is reported to stimulate osteoblastic differentiation of bone mesenchymal stem cells in ovariectomized mice by rescuing several gene expressions that were dysregulated including osteocalcin [12]. BuShen NingXin Decoction, a traditional Chinese medicinal compound modulated mesenchymal stem cell differentiation into osteoblasts in a postmenopausal osteoporotic mouse model with enhanced expression of osteoblastogenesis-related genes [14]. Similarly, Ginkgo biloba extract promotes osteogenic differentiation of human bone marrow mesenchymal stem cells in a pathway involving Wnt/ $\beta$-catenin signaling [13]. 

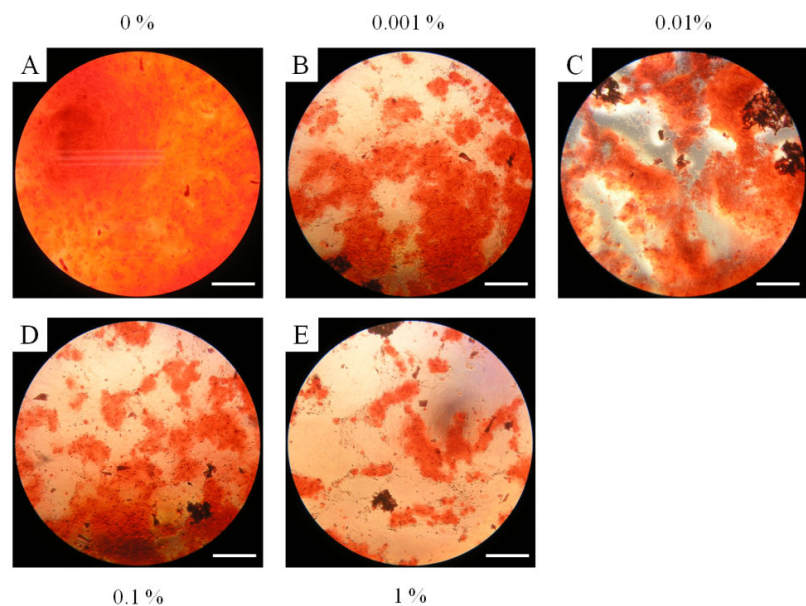

Figure 9. Results of Alizarin Red S staining on day 14 following treatment with different concentrations of BBT on osteogenic supplement. A) Control group (original magnification 100X); B) $0.001 \%$ group (original magnification $100 X$ ); C) $0.01 \%$ group (original magnification 100X); D) $0.1 \%$ group (original magnification 100X); E) $1 \%$ group (original magnification 100X). The bar indicates $400 \mu \mathrm{m}$.

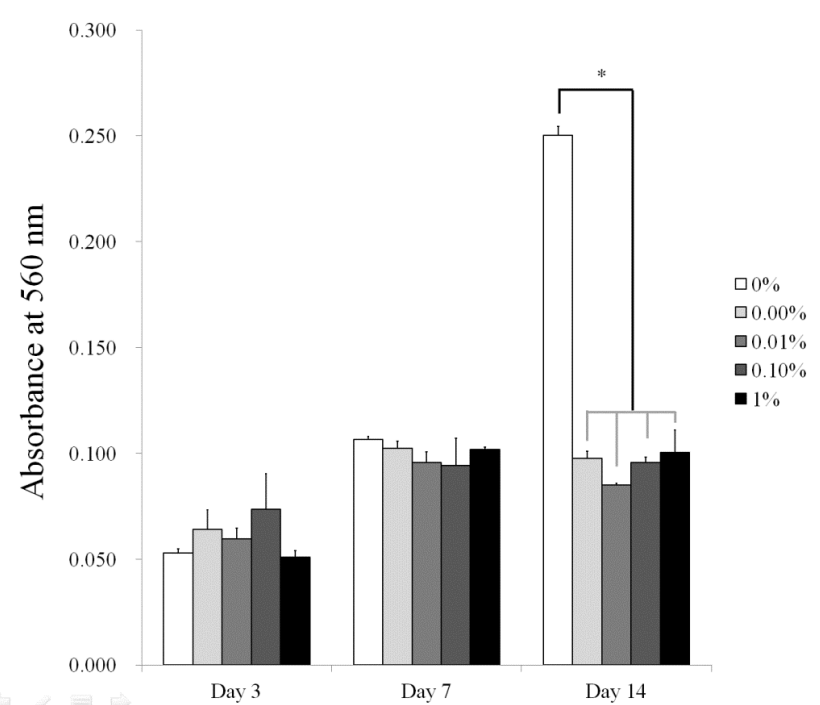

Figure 10. Quantitative results of Alizarin Red S staining on days 3, 7 and 14 .

Extract of beet roots, which is widely used in folk medicine as wound healing medicine have been applied with culture of mesenchymal stem cells for tissue engineering [15]. Herbal medicine has been considered as an alternative due to various reasons including antibiotic overuse and misuse [4]. Herbal medicines are considered very safe but there have been some concerns regarding the long-term risk of herb-induced liver injury in patients with liver dysfunction [3]. In this report, the decreased osteogenic differentiation of mesenchymal stem cells derived from gingival has been applied irrespective of different concentration of BBT. Previously, differentiation effects of individual herbal extracts have been tested on human mesenchymal stem cells mainly derived from bone marrow and elaborated on the plausible underlying mechanisms of action [5]. Mesenchymal stem cells may be isolated from various tissues including gingival, as used in this study [16-20]. Gingiva can be easily accessible and obtainable [10,21-25]. This procedure can be performed under local anesthesia and the obtained tissues are usually discarded in routine periodontal surgery $[11,26-31]$.

\section{Conclusion}

Bambusa tulda had influenced the osteogenic differentiation of the stem cells derived from the gingiva. Thus, the use of Bambusa tulda may produce adverse effects onto oral tissues. The concentration and application time of Bambusa tulda should be meticulously controlled to minimize the adverse effects.

\section{Acknowledgement}

This research was partly funded by the Ministry of Science, ICT and Future Planning, Republic of Korea government (NRF-2016K1A1A8A01939075), partly supported by Catholic Institute of Cell Therapy (CIC, Seoul, Korea) and partly supported by Basic Science Research Program through the National Research Foundation of Korea (NRF) funded by the Ministry of Science, Information and Communication $\begin{array}{llll}\text { Technology \& } & \text { Future Planning }\end{array}$ (NRF-2017R1A1A1A05001307).

\section{Conflict of Interests}

The authors report no conflicts of interest related to this study. The author does not have any financial interest in the companies whose materials are included in the article.

\section{Ethics Statement}

All procedures performed in studies involving human participants were in accordance with the ethical standards of the institutional and/or national research committee and with the 1964 Helsinki Declaration and its later amendments or comparable ethical standards.

\section{Informed Consent}

Informed consents were received from the participants.

\section{References}

1. Soumya V, Muzib YI, Venkatesh P. A novel method of extraction of bamboo seed oil (Bambusa tulda Druce) and its promising effect on metabolic symptoms of experimentally induced polycystic ovarian disease. Indian J Pharmacol 2016; 48: 162-167.

2. Guo M, Hu ZQ, Strong PJ, Smit AM3, Xu JW1, Fan J1, Wang HL4. Evaluating the Environmental Health Effect of Bamboo-Derived Volatile Organic Compounds through Analysis the Metabolic Indices of the Disorder Animal Model. Biomed Environ Sci 2015; 28: 595-605. 
3. Kuila A, Mukhopadhyay M, Tuli DK, Banerjee R. Accessibility of Enzymatically Delignified Bambusa tulda for Efficient Hydrolysis at Minimum Cellulase Loading: An Optimization Study. Enzyme Res 2011; 2011: 805795.

4. Sriraman S, Ramanujam GM, Ramasamy M, Dubey GP. Identification of beta-sitosterol and stigmasterol in Bambusa tulda (L.) Voss leaf extract using HPLC and its estrogenic effect in vitro. J Pharm Biomed Anal 2015; 115: 55-61.

5. Singla R, Soni S, Kulurkar PM, Kumari A, S Mahesh, Patial V, Padwad YS, Yadav SK. In situ functionalized nanobiocomposites dressings of bamboo cellulose nanocrystals and silver nanoparticles for accelerated wound healing. Carbohydr Polym 2017; 155: 152-162.

6. Ayyanar M, Ignacimuthu S. Ethnobotanical survey of medicinal plants commonly used by Kani tribals in Tirunelveli hills of Western Ghats, India. J Ethnopharmacol 2011; 134: 851-864.

7. Sharma J, Gairola S, Sharma YP, Gaur RD. Ethnomedicinal plants used to treat skin diseases by Tharu community of district Udham Singh Nagar, Uttarakhand, India. J Ethnopharmacol 2014; 158: 140-206.

8. Jeong SH, Lee JE, Jin SH, Ko Y, Park JB: Effects of Asiasari radix on the morphology and viability of mesenchymal stem cells derived from the gingiva. Mol Med Rep 2014; 10: 3315-3319.

9. Oh SM, Kim J, Lee J, Yi JM, Oh DS, Bang OS, Kim NS. Anticancer potential of an ethanol extract of Asiasari radix against HCT-116 human colon cancer cells in vitro. Oncol Lett 2013; 5: 305-310.

10. Cai B, Zhang AG, Zhang X, Ge WJ, Dai GD, Tan XL, Roodrajeetsing G, Cai JP. Promoting Effects on Proliferation and Chondrogenic Differentiation of Bone Marrow-Derived Mesenchymal Stem Cells by Four "Kidney-Tonifying" Traditional Chinese Herbs. Biomed Res Int 2015; 2015: 792161.

11. Park HJ, Lee K, Heo H, Lee M, Kim JW, Whang WW, Kwon YK, Kwon H. Effects of Polygala tenuifolia root extract on proliferation of neural stem cells in the hippocampal CA1 region. Phytother Res 2008; 22: 1324-1329.

12. Gu Q, Chen C, Zhang Z. Ginkgo biloba extract promotes osteogenic differentiation of human bone marrow mesenchymal stem cells in a pathway involving Wnt/betacatenin signaling. Pharmacol Res 2015; 97: 70-78.

13. Zhang N, Kang T, Xia Y, Wen Q, Zhang X, Li H, Hu Y, Hao H, Zhao D, Sun D, Yan Y, Zhang GX, Yang J. Effects of salvianolic acid B on survival, self-renewal and neuronal differentiation of bone marrow derived neural stem cells. Eur J Pharmacol 2012; 697: 32-39.

14. Park JB. Combination of simvastatin and bone morphogenetic protein-2 enhances the differentiation of osteoblasts by regulating the expression of phosphoSmad1/5/8. Exp Ther Med 2012; 4: 303-306.
15. Ji M, Bai C, Li L, Fan Y, Ma C, Li X, Guan W. Biological characterization of sheep kidney-derived mesenchymal stem cells. Exp Ther Med 2016; 12: 3963-3971.

16. Ha DH, Yong CS, Kim JO, Jeong JH, Park JB. Effects of tacrolimus on morphology, proliferation and differentiation of mesenchymal stem cells derived from gingiva tissue. Mol Med Rep 2016; 14: 69-76.

17. Ballini A, De Frenza G, Cantore S, Papa F, Grano M, Mastrangelo F, Tetè S, Grassi FR. In vitro stem cell cultures from human dental pulp and periodontal ligament: new prospects in dentistry. Int $\mathrm{J}$ Immunopathol Pharmacol 2007; 20: 9-16.

18. Nagatomo K, Komaki M, Sekiya I, Sakaguchi Y, Noguchi K, Oda S, Muneta T, Ishikawa I. Stem cell properties of human periodontal ligament cells. J Periodontal Res 2006; 41: 303-310.

19. Jin SH, Lee JE, Yun JH, Kim I, Ko Y, Park JB. Isolation and characterization of human mesenchymal stem cells from gingival connective tissue. J Periodontal Res 2015; 50: 461-467.

20. Park JB, Lee G, Yun BG, Kim CH, Ko Y. Comparative effects of chlorhexidine and essential oils containing mouth rinse on stem cells cultured on a titanium surface. Mol Med Rep 2014; 9: 1249-1253.

21. Zhang Q, Shi S, Liu Y, Uyanne J, Shi Y, Le AD. Mesenchymal stem cells derived from human gingiva are capable of immunomodulatory functions and ameliorate inflammation-related tissue destruction in experimental colitis. J Immunol 2009; 183: 7787-7798.

22. Jin SH, Kweon H, Park JB, Kim CH. The effects of tetracycline-loaded silk fibroin membrane on proliferation and osteogenic potential of mesenchymal stem cells. J Surg Res 2014; 192: e1-9.

23. Park JB, Kim YS, Lee G, Yun BG, Kim CH. The effect of surface treatment of titanium with sand-blasting/acidetching or hydroxyapaptite-coating and application of bone morphogenetic protein-2 on attachment, proliferation and differentiation of stem cells derived from buccal fat pad. Tissue Eng Regen Med 2013; 10: 115-121.

24. Fournier BP, Larjava H, Häkkinen L. Gingiva as a source of stem cells with therapeutic potential. Stem Cells Dev 2013; 22: 3157-3177.

25. Yang H, Gao LN, An Y. Comparison of mesenchymal stem cells derived from gingival tissue and periodontal ligament in different incubation conditions. Biomaterials 2013; 34: 7033-7047.

26. Wang MH, Jeong SH, Guo H, Park JB. Anti-inflammatory and cytotoxic effects of methanol, ethanol, and water extracts of Angelicae Dahuricae Radix. J Oral Sci 2016; 58: $125-131$.

27. Kim SY, An SY, Lee JS, Heo JS. Zanthoxylum schinifolium enhances the osteogenic potential of periodontal ligament stem cells. In Vitro Cell Dev Biol Anim 2015; 51: 165-173.

28. Jeong SH, Kim BB, Lee JE, Ko Y, Park JB. Evaluation of the effects of Angelicae dahuricae radix on the 
morphology and viability of mesenchymal stem cells. Mol Med Rep 2015; 12: 1556-1560.

29. Jeong SH, Lee JE, Kim BB, Ko Y, Park JB. Evaluation of the effects of Cimicifugae Rhizoma on the morphology and viability of mesenchymal stem cells. Exp Ther Med 2015; 10: 629-634.

30. Mukudai Y, Zhang M, Shiogama S, Kondo S, Ito C, Motohashi H, Kato K, Fujii M, Shintani S, Shigemori H, Yazawa K, Shirota T. Methanol and Butanol Extracts of Paeonia lutea Leaves Repress Metastasis of Squamous Cell Carcinoma. Evid Based Complement Alternat Med 2016; 2016: 6087213.

31. Jawaid T, Awasthi A, Kamal M. Estrogenic activity of a hydro-alcoholic extract of Bambusa arundinaceae leaves on female wistar rats. J Adv Pharm Technol Res 2015; 6: $19-24$.

\section{*Correspondence to}

Jun-Beom Park

Department of Periodontics

Seoul St Mary's Hospital

College of Medicine

The Catholic University of Korea

Republic of Korea 